\title{
Building the UPPA high capacity tensiometer
}

\author{
Joao Mendes ${ }^{1, a}$, Domenico Gallipoli ${ }^{1}$, Fabian Boeck ${ }^{2}$, Georg von Unold ${ }^{2}$ and Alessandro Tarantino ${ }^{3}$ \\ ${ }^{1}$ Laboratoire SIAME, Equipe Géomatériaux et Structures du Génie Civil, Université de Pau et des Pays de l'Adour, 64600 Anglet, France. \\ ${ }^{2}$ UMS GmbH, Gmunder Str. 37 D-81379 München, Germany. \\ ${ }^{3}$ Department of Civil and Environmental Engineering, University of Strathclyde, Glasgow, UK.
}

\begin{abstract}
High capacity tensiometers (HCTs) are sensors capable of directly measuring tensile pore water pressure (suction) in soils. HCTs are typically composed of a casing that encapsulates a high air entry value ceramic filter, a water reservoir and a pressure sensing element. Since the creation of the first HCT by Ridley and Burland in 1993 at Imperial College London, HCTs have been almost exclusively built and used in academic research. The limited use in industrial applications can be explained by a lack of unsaturated soil mechanics knowledge among engineering practitioners but also by the technical difficulties associated to the direct measurement of tensile water pressures beyond the cavitation limit of $-100 \mathrm{kPa}$. In this paper, we present the recent design and manufacture of a new HCT at the Université de Pau et des Pays de l'Adour (UPPA) in France. Different prototypes were tried by changing the main components of the device including the type of ceramic filter, pressure transducer and geometry of the external casing. In particular, two ceramic filters of distinct porosity, three pressure transducers with distinct materials/geometries and four casing designs were tested.
\end{abstract}

\section{Introduction}

High capacity tensiometers (HCT) can directly measure tensile pore water pressure (suction) in soils, which is an important variable for the hydro-mechanical characterization of these materials. The development of HCTs has so far been restricted to university research and has resulted in the development of prototypes capable of measuring relatively high values of suction up to $2000 \mathrm{kPa}$. The first HCT was developed in the 90's by Ridley and Burland [1] at Imperial College London. This HCT, whose design is shown in Figure 1, was able to measure values of suction greater than $1500 \mathrm{kPa}$. Since then, other HCTs with similar design have emerged, such as those described in [2-9] among others.

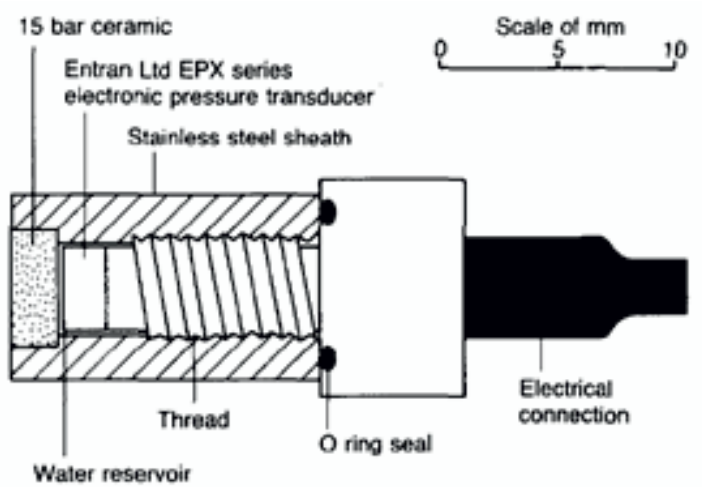

Figure 1. HCT developed by Ridley and Burland in 1993 [1].

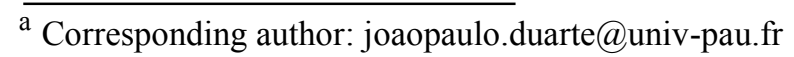

In general, HCTs are composed of a high air entry value (HAEV) ceramic filter, a water reservoir and a pressure transducer, all housed inside a casing made of stainless steel. Each of the above components can have a direct impact on the performance of HCTs.

The ceramic filter has the strongest influence on the measuring range [10] because the highest measurable value of suction strongly depends on the air entry value of the ceramic, which in turn increases with decreasing size of the largest ceramic pore.

As for the pressure transducer, ideally this should be symmetrical with respect to the sensing membrane so that the same calibration equation can be adopted regardless of the direction of deflection of the sensing membrane. Symmetry is desirable because calibration of HCTs is usually performed in the positive (compressive) pressure range and then extrapolated to the negative (tensile) pressure range [5]. Furthermore, the measuring range of the pressure transducer should be at least equal to the air entry value of the ceramic filter.

Mendes and Buzzi [9] showed that, contrary to previous suggestions [1], the volume of the water reservoir does not need to be very small in order to measure high values of suction. Nevertheless, HCTs should always be thoroughly saturated by de-aired water and a particularly careful saturation procedure should be adopted when starting from an initially dry HCT, as further discussed later.

In general, the external casing is the component that has the least influence on the performance of HCTs, provided that this is sufficiently stiff to protect the sensor 
from external loads. In some prototypes, the casing is in direct contact with the water reservoir, whose dimensions therefore depend on the design of the casing (see Figure 1).

This article presents five different HCT prototypes developed at the Université de Pau et des Pays de l'Adour (UPPA) in France within the framework of a collaborative industry-academia project on Monitoring systems to Assess Geotechnical Infrastructure subjected to Climatic hazards (MAGIC). The project, which involves three universities and four small-medium enterprises across Europe, is funded by the European Commission through a "Marie Curie" Industry Academia Partnerships and Pathways (IAPP) network (http://www.magic-iapp.com/).

Various combinations of ceramic filters, pressure transducers, casing designs and water reservoir sizes were experimented in this work. In particular, the different prototypes make use of: a) two different ceramic filters with distinct air entry values of $700 \mathrm{kPa}$ and $1500 \mathrm{kPa}$, respectively, b) three different pressure transducers, namely a flush diaphragm ceramic transducer, a cavity diaphragm ceramic transducer and a flush diaphragm stainless steel transducer and c) four different stainless steel casing dimensioned to accommodate the transducer and the ceramic as well as to create the water reservoir in four out of five prototypes. The maximum attainable suction of each prototype was measured by means of evaporation tests during which the face of the ceramic filter was exposed to the atmosphere so that water could evaporate and suction could increase. As expected, the prototypes incorporating ceramic filters with an air entry value of $1500 \mathrm{kPa}$ were able to measure suctions greater than $1500 \mathrm{kPa}$ while those incorporating a ceramic filter with an air entry value of $700 \mathrm{kPa}$ attained suctions of around $700 \mathrm{kPa}$.

\section{Materials}

The porosity characteristics of the two ceramic filters (referred as ceramics $A$ and $G$ in the following) were studied with reference to the measuring range of the respective HCTs. Ceramic A is made of typical pottery clay, mainly kaolinite, while ceramic G contains predominantly alumina. The microstructure of the two ceramics was studied by mercury intrusion porosimetry (MIP) and nitrogen absorption (NA).

Table 1 summarizes the porosimetry data of the two ceramics. Ceramic G has significantly lower porosity and higher density than ceramic A. This is also consistent with the fact that ceramic $\mathrm{G}$ is much harder to cut or break than ceramic A [10].

The results of the MIP and NA tests are presented in Figure 2, which also shows for comparison the pore sizes corresponding to the air entry values of $500 \mathrm{kPa}$ and 1500 $\mathrm{kPa}$ (estimated according to the Young-Laplace equation). The pore sizes of ceramic $G$ cover the range from $100 \mathrm{~nm}$ to $300 \mathrm{~nm}$ and are mono-disperse around a value of 230 $\mathrm{nm}$, while the pore sizes of ceramic A cover a smaller range from $1 \mathrm{~nm}$ to $190 \mathrm{~nm}$ and are poly-disperse without a dominant value.
Table 1. Porosimetry data of ceramics A and G.

\begin{tabular}{|c|c|c|c|c|}
\hline $\begin{array}{c}\text { Ceramic } \\
\text { type }\end{array}$ & $\begin{array}{c}\text { Largest } \\
\text { pore } \\
\text { diameter } \\
\text { nm }\end{array}$ & $\begin{array}{c}\text { Bulk } \\
\text { density }^{\#} \\
\text { g/cm }\end{array}$ & $\begin{array}{c}\text { Apparent } \\
\text { (skeletal) } \\
\text { density } \\
\text { g/cm }\end{array}$ & $\begin{array}{c}\text { Porosity } \\
\%\end{array}$ \\
\hline $\mathrm{A}$ & 165 & 1.31 & 1.88 & 30.1 \\
\hline G & 250 & 2.68 & 3.11 & 13.7 \\
\hline
\end{tabular}

Table 2. Pressure transducer characteristics.

\begin{tabular}{|c|c|c|c|}
\hline Designation & $\begin{array}{c}\text { Ceramic } \\
\text { flush } \\
\text { diaphragm }\end{array}$ & $\begin{array}{c}\text { Ceramic } \\
\text { cavity } \\
\text { diaphragm }\end{array}$ & $\begin{array}{c}\text { Stainless steel } \\
\text { flush } \\
\text { diaphragm }\end{array}$ \\
\hline Short name & CFD & CCD & SSFD \\
\hline $\begin{array}{c}\text { Sensor } \\
\text { type }\end{array}$ & \multicolumn{2}{|c|}{ Piezoresistive } & Strain gauge \\
\hline $\begin{array}{c}\text { Pressure } \\
\text { reference }\end{array}$ & $\begin{array}{c}\text { Relative / } \\
\text { Sealed } \\
\text { relative }\end{array}$ & Relative & $\begin{array}{c}\text { Sealed } \\
\text { relative }\end{array}$ \\
\hline $\begin{array}{c}\text { Accuracy } \\
\text { (\%FS) }\end{array}$ & \multicolumn{3}{|c|}{0.5} \\
\hline $\begin{array}{c}\text { Pressure } \\
\text { range (kPa) }\end{array}$ & \multicolumn{3}{|c}{1} \\
\hline
\end{tabular}

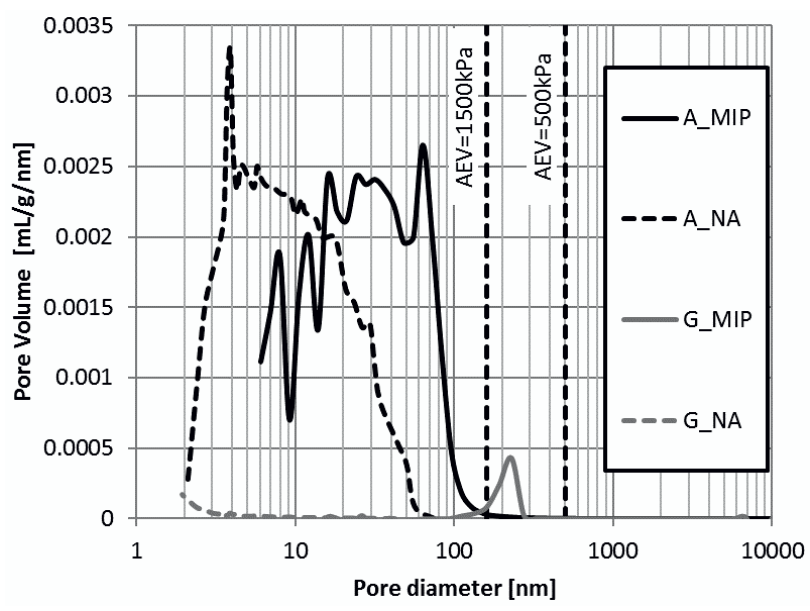

Figure 2. Pore size distributions of ceramics $A$ and $G$ by mercury intrusion porosimetry (MIP) and nitrogen adsorption (NA)

Three different types of transducers, all capable of measuring relative pressures with a range of $2 \mathrm{MPa}$, were used in this work: a) a ceramic flush diaphragm transducer (CFD), b) a ceramic cavity diaphragm transducer (CCD) and c) a threaded stainless steel flush diaphragm transducer (SSFD). The characteristics of these three pressure transducers are summarized in Table 2 while their incorporation in the different designs is shown in Figure 3.

All prototypes casings were machined with a lathe from SS316L low carbon stainless steel to prevent corrosion in those cases where the water reservoir was in direct contact with the casing. 


\section{HCT prototypes}

Figure 3 shows the schematics of the five prototype designs pursued in this work (referred in the following as prototypes 1-5). The first prototypes to be built were number 1 and 2 . These prototypes are very similar in conception, i.e. they employ identical CFD pressure transducers and stainless steel casings. However, prototype 1 was fitted with ceramic $\mathrm{G}$ while prototype 2 was fitted with ceramic A. The transducers and the ceramics were sealed in place by gluing around their perimeter inside the respective slots. The casings were designed to accommodate a small water reservoir of about $40 \mathrm{~mm}^{3}$ between the pressure transducer and the ceramic by making the transducer slot slightly deeper than the transducer itself.
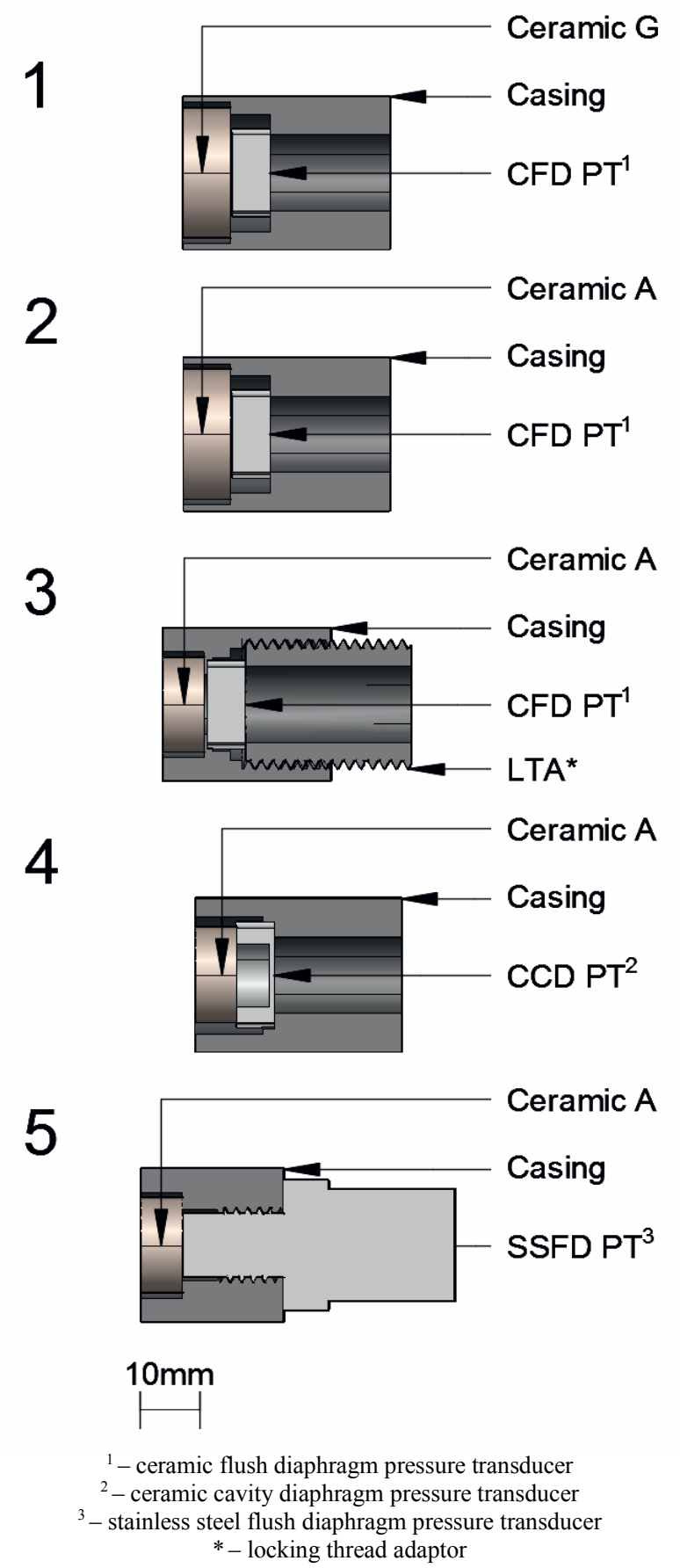

Figure 3. Schematics of HCT prototypes
Prototype 3 was designed as an improvement over prototypes 1 and 2 . In this case, a CFD pressure transducer and ceramic A were used. The water reservoir was integrated in the design of the casing by machining a thin protruding lip that separates the ceramic filter from the transducer, thus resulting in a water reservoir of about $40 \mathrm{~mm}^{3}$. To prevent dislodgement of the transducer when subjected to large positive pressures during saturation, a threaded adaptor (LTA in Figure 3) was screwed on the back of the casing to tightly secure the transducer in place by pushing it against the protruding lip.

In prototype 4 , ceramic A was directly glued on a ceramic cavity diaphragm transducer (CCD). This transducer incorporates a small cavity inside its body. It is therefore this cavity that forms the water reservoir rather than the external casing as in other prototypes. This also means that, in this design, the water reservoir has a relatively large volume of about $430 \mathrm{~mm}^{3}$. Unlike previous prototypes, here the external casing has the only purpose of protecting the transducer and attached ceramic filter and is not in direct contact with the water reservoir.

In prototype 5 , ceramic A was used in association with a threaded stainless steel flush diaphragm pressure transducer (SSFD). This prototype resembles closely the designs developed by [1] and [11]. Similarly to prototypes $1-3$, the water reservoir has a size of about $40 \mathrm{~mm}^{3}$ and is in direct contact with the casing. The size of the reservoir can be controlled during construction by adjusting the position of the transducer with its thread.

\section{Saturation and calibration of the HCTs}

\subsection{Saturation}

Good saturation is crucial for the performance of HCTs. As suggested by Marinho and Chandler [12], initial saturation of HCTs is particularly important and should include application of high vacuum followed by water flooding and pressurization. Application of high vacuum is necessary to minimise the amount of trapped air inside both the ceramic and the reservoir, while subsequent water pressurization helps dissolving any remaining air pocket.

In this work, the initial saturation of all prototypes followed the above recommended procedure. The dry HCTs were first exposed to a high vacuum for about 1 hour to evacuate any trapped air. Afterwards, they were flooded by de-aired water and pressurized at $2990 \mathrm{kPa}$ overnight to dissolve any remaining air pocket. For the HCTs with a small water reservoir (prototypes 1, 2, 3 and 5), this procedure was more than adequate to achieve full saturation. However, for prototype 4 , it was necessary to increase the duration of the pressurization stage to $96 \mathrm{hrs}$ because of the larger reservoir size (this duration will also depend on the level of vacuum that is applied prior to water pressurization).

\subsection{Calibration of HCTs}

Following previous research [5], the calibration of all HCTs was performed in the positive (compressive) 
pressure range and then extrapolated to the negative (tensile) pressure range.

A positive pressure cycle of $2990 \mathrm{kPa} \rightarrow 50 \mathrm{kPa} \rightarrow 2990$ $\mathrm{kPa}$ was imposed to all five prototypes and the resulting regression lines of pressure against voltage are shown in Figure 4. The calibrations are linear in the positive pressure range with typical hysteresis of $0.04 \%$ for prototypes $1,3,4$ and 5 and $0.02 \%$ for prototype 2 . This suggests that, if the HCTs are properly saturated, the effect of hysteresis can be almost neglected. It is also interesting to note that, regardless of the particular prototype design (large/small reservoir, type of ceramic filter or pressure transducer), the magnitude of hysteresis was very similar.

\section{Results}

After saturation and calibration, all prototypes were subjected to evaporation tests to determine the measuring range. In evaporation tests, a fully saturated HCT is exposed to the atmosphere so that the face of the ceramic filter (i.e. the measuring face) is allowed to dry. As the ceramic filter dries, water is pulled from the reservoir and the HCT reads increasingly larger values of tensile water pressures over time until cavitation. When cavitation occurs, air pockets form into the water reservoir resulting in a sudden reduction of the tensile pressure to around $100 \mathrm{kPa}$. The value of the largest tensile pressure measured immediately before cavitation is taken as the limit of the measuring range.

\subsection{Ceramic A versus ceramic $\mathrm{G}$}

Prototypes 1 and 2 incorporate identical pressure transducers, casings and water reservoir sizes but different ceramic filters. Prototype 1 used ceramic $G$ while prototype 2 used ceramic A. Typical evaporation tests on both prototypes are shown in Figure 5, where it can be observed that prototype 2 has a higher measuring range (about $-2000 \mathrm{kPa}$ ) than prototype 1 (about $-700 \mathrm{kPa}$ ). As previously mentioned, this difference is due to the distinct ceramic filters and, in particular, to the distinct sizes of their largest ceramic pores. As shown in Figure 2 and Table 2, the size of the largest pore is smaller in ceramic A than in ceramic G. Ceramic A can therefore sustain higher water tensions and, hence, achieves a larger measuring range compared to ceramic G. For this reason, subsequent prototypes 3, 4 and 5 were all built with ceramic A.

\subsection{Casing design for CFD pressure transducer}

The construction of further HTCs based on prototype 2 was rather unsuccessful, with five out of eight HCTs not working correctly. The HCTs failed during repressurization at $2990 \mathrm{kPa}$ after the first evaporation test because water leaked along the sides of the CFD transducer into the back. Probably, the relatively high water tension measured during evaporation pulled the transducer towards the reservoir, thus damaging the glue seal around the perimeter of the transducer. To prevent this, prototype 3 was developed by designing a casing that incorporated a thin lip protruding inside to separate the ceramic filter from the transducer, thus forming a gap for the water reservoir. The transducer is locked against this protruding lip by means of a threaded adaptor screwed on the back of the casing. The protruding lip prevents movement of the transducer towards the reservoir when tensile pressures are present while the threaded adaptor impedes movement away from the reservoir during positive pressurization. This means that the construction of prototype $3 \mathrm{HCTs}$ is slightly more complicate than prototypes 1 and 2 . A typical evaporation test performed on prototype 3 is shown in Figure 6, which suggests a measuring range of $-1800 \mathrm{kPa}$.

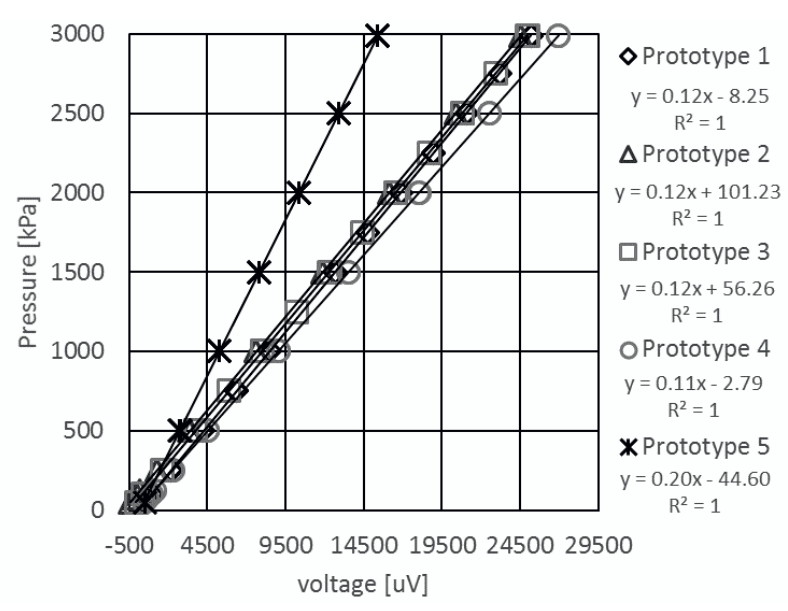

Figure 4. Calibration curves of the five prototypes.

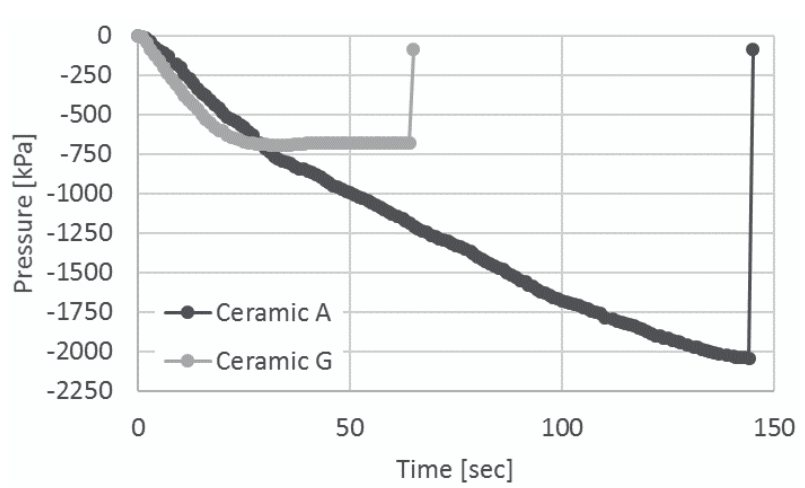

Figure 5. Evaporation tests of prototype 1 (ceramic $G$ ) and prototype 2 (ceramic A).

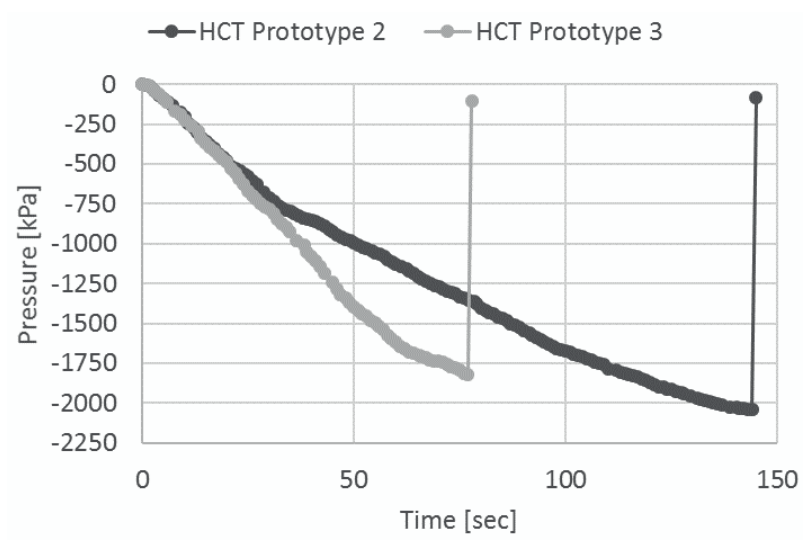

Figure 6. Evaporation tests of prototype 2 and prototype 3. Prototype 3 seems to react quicker than prototype 2, though it has a slightly smaller measuring range. This 
difference is not believed to be a cause of the design, but rather of the inherent variability of the ceramic filters used in each prototype.

\subsection{Large reservoir versus small reservoir}

Unlike prototypes 1, 2 and 3, the water reservoir of prototype 4 is an integral part of the CCD transducer and is therefore relatively large $\left(430 \mathrm{~mm}^{3}\right)$. This also means that construction of prototype 4 is much simpler as the ceramic filter is directly glued to the pressure transducer, eliminating all problems related to potential water leaks when using CFD transducers.

Figure 7 shows the results of a typical evaporation test performed with prototype 4. Inspection of Figure 7 suggests a measuring range of around $-1800 \mathrm{kPa}$, which is comparable to that of prototypes 2 and 3. This is consistent with the findings of Mendes and Buzzi [9], who suggested that the reservoir size does not have a marked influence on measuring range. However, the response during evaporation was slower for prototype 4 than for other prototypes. In prototype 4, cavitation occurred after 275 seconds, compared to 145 seconds and 80 seconds for prototypes 2 and 3 , respectively.

\subsection{Ceramic pressure transducer versus stainless steel pressure transducer}

Most commercially available pressure transducers are made of either metal or ceramic. In order to study the influence of the material of the transducer on the response of HCTs, prototype 5 was built by using a stainless steel flush diaphragm transducer (SSFD). Prototype 5 was designed to have a water reservoir of similar dimensions as in prototypes 2 and 3 (i.e. about $40 \mathrm{~mm}^{3}$ ). However, prototypes 2 and 3 incorporated a ceramic flush diaphragm transducer (CFD) instead of a stainless steel one.

Figure 8 shows some typical evaporation tests performed with prototypes 2, 3 and 5. Figure 8 suggests that all prototypes have similar measuring ranges varying between $-1800 \mathrm{kPa}$ and $-2100 \mathrm{kPa}$. The response time was found to be similar for all three prototypes up to a suction of $-800 \mathrm{kPa}$. After that, the response of prototype 2 became gradually slower as suction increased while prototypes 3 and 5 continued to dry at an approximately constant rate. In general, it appears that there are no significant differences in terms of both measuring range and response time between stainless steel and ceramic pressure transducers.

\section{Conclusions}

Five different high capacity tensiometer prototypes were designed and manufactured at the Université de Pau et des Pays de l'Adour in France within the framework of an EU-funded collaboration between industry and academia.

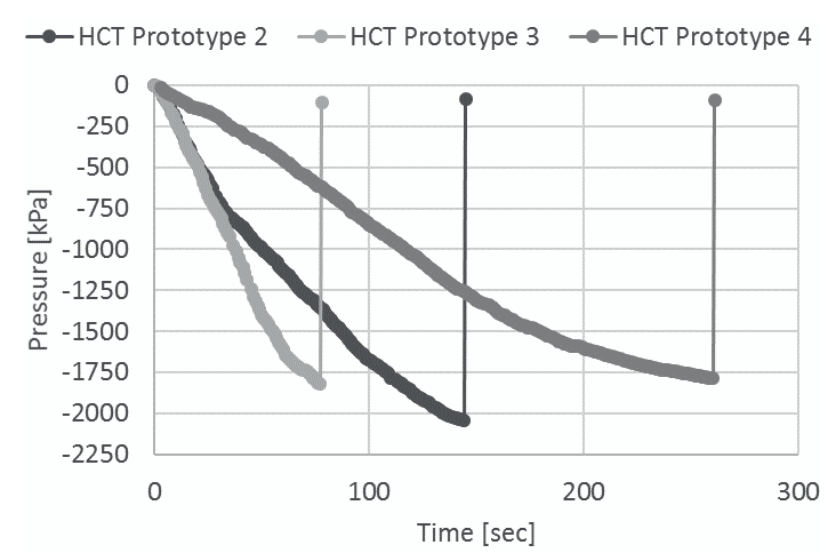

Figure 7. Evaporation tests with small water reservoir (prototypes 2 and 3) and large water reservoir (prototype 4).

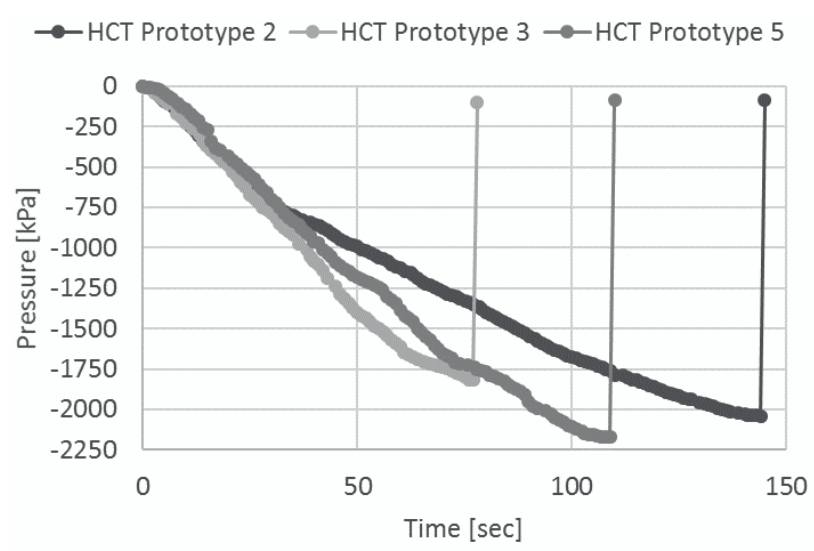

Figure 8. Evaporation tests with ceramic pressure transducer (prototypes 2 and 3) and stainless steel pressure transducer (prototype 5).

The prototypes differ in the choice of: a) ceramic filters (two ceramic filters were used with air entry values of 700 $\mathrm{kPa}$ and $1500 \mathrm{kPa}$, respectively), b) water reservoir size (two reservoir sizes equal to $40 \mathrm{~mm}^{3}$ and $430 \mathrm{~mm}^{3}$ were investigated), c) geometry of the pressure transducers (two transducer geometries were explored consisting of a flush sensing diaphragm and a cavity sensing diaphragm) and d) material of the transducer (two different transducer materials were considered, i.e. ceramic and stainless steel). This allowed a detailed study of the influence of the above factors on the performance of high capacity tensiometers and, in particular, on the measuring range and response time during evaporation tests.

Results show that the type of ceramic filter has the strongest influence on measuring range (Figure 5) and, in particular, the measuring range increases as the air entry value of the ceramic increases. Therefore, the tensiometer prototypes incorporating a ceramic filter with an air entry value of $700 \mathrm{kPa}$ measured pore water tensions up to about $-700 \mathrm{kPa}$ while the prototypes incorporating a ceramic filter with an air entry value of $1500 \mathrm{kPa}$ exhibited a much larger measuring range in the region of $1800-2100 \mathrm{kPa}$. Mercury intrusion porosimetry and nitrogen adsorption tests also showed that the air entry value of a ceramic filter tends to increase as the size of the largest pore within the ceramic decreases.

The volume of the water reservoir has a noticeable effect on response time, with a larger reservoir tending to 
produce a slower response during evaporation tests. In addition, a larger reservoir requires significantly longer pressurization times during initial saturation of the tensiometer. Finally, the geometry and material of the pressure transducer have a relatively small influence on performance in terms of both measuring range and response time.

In terms of ease of manufacture, not all prototypes showed the same success rate during repeated construction. In particular, the first two prototypes making use of a ceramic flush diaphragm transducer tended to leak when re-pressurized after cavitation. This was probably due to the pull exerted by water tension on the transducer. This pull is transferred from the transducer to the adjacent glue joint, which has the double purpose of fixing the transducer to the casing and sealing the gap around its perimeter. The repeated pulling action during subsequent cavitations produces shearing of the surrounding glue layer and eventually damages it resulting in the creation of small pathways that allow water to leak from the front to the back of the transducer. This problem was overcome in a third prototype by blocking the movement of the pressure transducer with a locking system that held the transducer in place without relying on the strength of the glue. The last two prototypes did not suffer from similar malfunction because, in one case, the ceramic filter was directly attached to a cavity diaphragm transducer and, in the other case, the transducer incorporated a thread and could therefore be securely locked inside the casing.

The preliminary study has shown that, independently of design, all prototypes were able to reach values below the nominal air entry value of the porous ceramic during evaporation tests. However, further studies, i.e. soil suction measurements, are still required to properly evaluate and access the best design for a high capacity tensiometer.

\section{Acknowledgements}

The financial contribution of the European Commission to this research through the Marie Curie Industry-Academia Partnership and Pathways Network MAGIC (Monitoring systems to Assess Geotechnical Infrastructure subjected to Climatic hazards) - PIAPP-GA-2012-324426 - is gratefully acknowledged.

\section{References}

1. A.M. Ridley and J.B. Burland, Géotechnique 43(2): 321-324 (1993).

2. A.M. Ridley and J.B. Burland, Advances in Site Investigation Practice. 510-520 (1995).

3. Y. Guan and D.G. Fredlund, Can. Geotech. J., 34(4): 604-614 (1997).

4. I. Meilani, H. Rahardjo, E.C. Leong and D.G. Fredlund, Can. Geotech. J. 39: 1427-1432 (2002).

5. A. Tarantino and L. Mongiovì, Proc. 3rd Int. Conf. on Unsaturated soils, Recife, Brasil 1: 319-324 (2002).

6. W.A. Take and M.D. Bolton, Géotechnique 54(3): 159-172 (2003).

7. S.D.N. Lourenço, D. Gallipoli, D.G. Toll, C. Augarde, F. Evans and G.M. Medero, Géotechnique 58(8): 659668 (2008).

8. Y.J. Cui, A. Tang, A. Mantho, and E. De Laure, Geotech. Test. J. 31(1): 95-100 (2008).

9. J. Mendes and O. Buzzi, Can. Geotech. J. 50(5): 550556 (2013).

10. J. Mendes, D. Gallipoli, F. Plantier and D. Grégoire, Rencontres Universitaires de Génie Civil, Bayonne, France $(2015)<$ hal-01167597>.

11. J. Mendes and O. Buzzi, Proc. UNSAT 2014, Unsaturated Soils: Research \& Applications, Sydney, Australia: 1611-1616 (2014).

12. F.A.M. Marinho and R.J. Chandler, Géotechnique 44(3): 551-556 (1994). 